\title{
EL PANÓPTICO DE BENTHAM Y LA INSTRUMENTALIZACIÓN DE LOS DERECHOS HUMANOS
}

\author{
Pablo Beytía Reyes* \\ doi:10.11144/Javeriana.uph34-68.pbdh
}

\begin{abstract}
RESUMEN
Este artículo revisa los fundamentos del utilitarismo de Jeremy Bentham y las principales críticas a esta doctrina, profundizando en aquella que sostiene su incompatibilidad con el respeto irrestricto de los derechos humanos. Insertándose en esta problemática, analiza una paradigmática propuesta política del filósofo inglés: el panóptico, proyecto arquitectónico formulado por Bentham a finales del siglo XVIII con el fin de reformar el sistema penitenciario europeo. A partir del análisis del Panóptico -que se descubre como una aplicación coherente del utilitarismo benthamiano-, se postula que: a) esta doctrina fomenta un trato humanitario; b) los derechos humanos no quedan garantizados, sino condicionados al grado de beneficio colectivo que generen; c) este utilitarismo supone un cuestionamiento por la universalidad e irrevocabilidad de dichos preceptos.
\end{abstract}

Palabras clave: utilitarismo; derechos humanos; justicia social; Jeremy Bentham; panóptico

* Pontificia Universidad Católica de Chile, Santiago de Chile, Chile Correo electrónico: ptbeytia@uc.cl

Para citar este artículo: Beytía Reyes, P. (2017). El panóptico de Bentham y la instrumentalización de los derechos humanos. Universitas Philosophica, 34(68), pp. 173-196. ISSN 0120-5323, ISSN en línea 2346-2426. doi:10.11144/Javeriana.uph34-68.pbdh 


\title{
BENTHAM'S PANOPTICON AND INSTRUMENTALIZATION OF HUMAN RIGHTS
}

\author{
Pablo Beytía Reyes
}

\begin{abstract}
This paper reviews the foundations of Jeremy Bentham's utilitarianism and the main criticisms to this doctrine, especially those which deem it incompatible with unconditional respect of human rights. Bentham's Panopticon, his proposal on prison reform published in the late eighteenth century, is discussed. Based on the analysis of the Panopticon -which is a consistent application of Bentham utilitarianism-, the author concludes that a) this doctrine promotes a humanitarian approach, although b) human rights are not guaranteed, but conditioned to the provided level of collective benefit; and c) Bentham's utilitarianism questions the universality and irrevocability of human rights.
\end{abstract}

Key words: utilitarianism; human rights; social justice; Jeremy Bentham; panopticon 
El UTILITARISMo Ha SIDO una de las filosofías éticas más influyentes de los últimos siglos. A más de doscientos años de An Introduction to the Principles of Morals and Legislation, publicado por Jeremy Bentham en 1780, los pensadores más relevantes en los debates morales o políticos contemporáneos -como Robert Nozick, John Rawls, Ronald Dworkin, Amartya Sen o Michael Sandel- siguen situando sus ideas en comparación con las de los utilitaristas ${ }^{1}$. Ello no es de extrañar, dado que esta teoría no solo ha sido muy relevante en la filosofía moral y política moderna, sino también en la fundamentación tradicional de la economía del bienestar y de la política pública (Sen 2000), llegando incluso a equipararse intuitivamente con la teoría económica (Posner 1998).

Su notable influencia no implica, sin embargo, que el utilitarismo no haya estado sujeto a diversas críticas desde sus inicios. Ya Kant (2007) afirmaba que la inquietud utilitarista por determinar con seguridad y universalidad qué acción fomenta la felicidad de un ser racional "es totalmente insoluble" (p. 33). Casi ochenta años después, John Stuart Mill (1991) hizo notar una queja diferente, orientada hacia la conservación de la dignidad humana:

Tal teoría de la vida provoca en muchas mentes, y entre ellas algunas de las más estimables en sentimientos y objetivos, un fuerte desagrado. Suponer que la vida no posea (tal como ellos lo expresan) ninguna finalidad más elevada que el placer -ningún objeto mejor y más noble de deseo y búsquedalo califican como totalmente despreciable y rastrero, como una doctrina solo digna de los puercos, a los que se asociaban los seguidores de Epicuro en un principio. (p.46)

Las críticas actuales no son menos duras y cuestionan los tres pilares del utilitarismo: el enfoque en el logro del bienestar, la evaluación de las consecuencias y el cálculo de la felicidad individual y colectiva ${ }^{2}$. Dentro de estos reproches,

1 Un importante ejemplo de esto es el artículo de Sen (2006) "Reason, Freedom and Well-Being", en donde el autor se hace cargo directamente de las similitudes que le atribuyen con respecto a John Stuart Mill. También es ilustrativo el artículo de Mäkinnen y Kakkurri-Knuuttila (2013), que muestra cómo actualmente se sigue discutiendo la cercanía de Rawls con el utilitarismo.

2 Estos son los pilares distinguidos por Sen (2000). La explicación y las críticas a cada uno de estos argumentos son detallados posteriormente. 
ocupa un lugar especial la crítica que argumenta una incompatibilidad lógica entre el utilitarismo y la defensa irrestricta de los derechos humanos. Según este argumento, no sería posible sostener, al mismo tiempo, el principio de justicia social utilitarista y la inviolabilidad de la persona (Rawls, 1995 [1971]; Hart, 1979; Frey, 1984a; Sen, 2000; Sandel, 2011). Esta incompatibilidad ya era trabajada por John Stuart Mill en 1863 y hasta la fecha siguen existiendo numerosas discusiones al respecto 3 .

En este ensayo se retomará este clásico debate desde una arista particular. Una de las características del utilitarismo clásico es que no solamente fue formulado en principios, sino también con propuestas políticas concretas ${ }^{4}$. Dentro de estas últimas, destaca el panóptico, un proyecto arquitectónico orientado a reestructurar las cárceles Europeas que fue diseñado y difundido por Jeremy Bentham desde 1786 con la intención de disminuir el mal social, expandiendo la inspección y optimizando el uso de los recursos estatales. El nivel de convicción, expectativa e importancia que le atribuía Bentham a este proyecto puede observarse nítidamente en la carta que le escribió a un diputado francés en 1791, con el objetivo de que la Asamblea Nacional conviniera construir un panóptico en Francia:

¿Os interesaría saber, señor, hasta qué punto ha llegado mi convencimiento sobre la importancia de ese plan de reforma y sobre los grandes éxitos que de él pueden esperarse? Permítaseme construir una prisión con ese modelo, y yo seré carcelero de ella. Veréis en dicha memoria que este carcelero no pide ningún salario y nada costará a la nación. (Bentham, 1980, p. 37)

Si bien Bentham no logró que se construyera ningún panóptico durante su vida, más tarde este desarrollo arquitectónico se aplicó con variaciones en algunos países, no solamente en cárceles, sino también en otros proyectos de bienestar

3 Véase, por ejemplo, la discusión entre Richard Posner (1979) y Ronald Dworkin (1980), luego de que el primero defendió el principio de maximización como base para una teoría prescriptiva del Derecho. Posteriormente, tuvo relevancia el debate sobre utilidad y derechos humanos integrado en la revista Utilitas (1998), Vol. 10, No 2 (Cambridge University Press). En la actualidad esta discusión ha sido impulsada por la proliferación de estudios científicos sobre la felicidad; véase, por ejemplo, la crítica de Amartya Sen (2014) a la postura política de Richard Layard (2005).

4 Giovanni Sartori (2002) destaca tres defensas políticas que defendieron tradicionalmente los utilitaristas: el gobierno representativo, el sufragio universal masculino y el liberalismo económico. 
público 5 . Pues bien, ¿entra esta propuesta arquitectónica, ideada con el más puro espíritu utilitarista, en conflicto con los derechos humanos? ¿Sería posible encontrar en la materialización del panóptico - esto es, no en los principios filosóficos del utilitarismo, sino en una de sus propuestas más paradigmáticas y concretas para la política pública- alguna incompatibilidad con el principio de inviolabilidad de la persona? Es esta la interrogante que intentará resolver este ensayo.

En la primera sección, se revisarán los puntos básicos del utilitarismo de Jeremy Bentham, considerado como un representante clásico de esta doctrina. Luego, se expondrán los argumentos de quienes sostienen una incompatibilidad entre el utilitarismo y los derechos humanos. Posteriormente, se describirá el Panóptico propuesto por Bentham y las señales de compatibilidad e incompatibilidad con los derechos humanos. Finalmente, se evaluará si este desarrollo arquitectónico entra o no en conflicto con la defensa irrestricta de estos preceptos.

\section{El utilitarismo clásico de Jeremy Bentham}

Si Bien las RaÍCes Del UTILITARISmo podrían remontarse a los escritos de Francis Hutcheson (2004 [1726]), Joseph Priestley (1771), William Paley (2002 [1785]) o William Godwin (1793) -otros las remontan a David Hume (2006 [1751]) e incluso a Epicuro (1999 [siglo III a. C.])-, pocas personas discutirían que Jeremy Bentham es uno de los fundadores de esta doctrina y, seguramente, quien más contribuyó a popularizarla en su versión clásica. Es por ello que Richard Posner (1998), por ejemplo, cuando trata de evaluar la relación entre la economía y el utilitarismo, señala que este último "no alcanzó un grado de desarrollo comparable al de la economía smithiana hasta que apareció la obra de Bentham" (p. 211).

Las bases antropológicas del utilitarismo de Bentham fueron introducidas en su libro An Introduction to the Principles of Morals and Legislation, en donde el filósofo inglés sostuvo:

La naturaleza ha colocado a la humanidad bajo el gobierno de dos amos soberanos, el dolor y el placer. Les corresponde solo a ellos señalar lo que debemos

5 Un caso de aplicación se encuentra en Chile donde se construyeron 58 panópticos destinados a albergar 3642 viviendas sociales entre los años 1975 y 1998 (MINVU, 2014). 
hacer, así como determinar lo que haremos. Por un lado, la norma del bien y del mal, por el otro la cadena de causas y efectos, están sujetos al trono de ellos. Nos gobiernan en todo lo que hacemos, en todo lo que decimos, en todo lo que pensamos; todo esfuerzo que hagamos para librarnos de nuestra sujeción servirá solo para demostrarla y confirmarla. (Bentham, 2000, p. 14)

Esta observación antropológica -muy similar a la sostenida por el epicureísmo (Cortina, 2000) - podría ser resumida en dos premisas: los polos de la utilidad, representados por el placer y el dolor, gobiernan inexorablemente a) la naturaleza del actuar humano -sus determinantes, causas y efectos- y b) la conducta ética -lo que se debe hacer, el bien y el mal- ${ }^{6}$. De esta forma, se comprende el alcance general, metafísico y moral de los fundamentos sostenidos inicialmente por Bentham.

Introduciéndose en el plano ético, el filósofo inglés propone el principio de utilidad, que consiste en aprobar o desaprobar cualquier acción, individual o gubernamental, según aumente o disminuya la felicidad de aquellos cuyo interés está en juego. Como bien subraya John Stuart Mill (1991 pp. 45-46), con base en esta norma ética se consideran correctas las acciones que tienden a promover la felicidad e incorrectas las que se inclinan a promover lo contrario.

El concepto de utilidad es entendido por Bentham (2000, pp. 14-15) de una manera específica. Se refiere a la propiedad que tienen los objetos de producir beneficio, ventaja, placer, bien o felicidad -sin establecer diferencia entre estos fenómenos-, o para prevenir el daño, el dolor, el mal o la infelicidad. Esta propiedad no se aplica únicamente al interés individual, sino también a la comunidad en general, entendida esta como un cuerpo ficticio compuesto por personas individuales. De esta forma, desde la conceptualización misma de la utilidad, Bentham abre el utilitarismo hacia la dimensión política: para los gobernantes y legisladores es posible perseguir el interés colectivo. Lo colectivo, cabe aclarar, no es entendido como un fenómeno emergente, irreductible a las personas que participan del grupo social. Por el contrario: mostrando su afiliación con una ontología social individualista -o conflacionista ascendente, como ha sido

6 Ante ambas premisas, cabría preguntarse: ¿para qué es necesario un gobierno ético utilitarista, si la acción ya es gobernada por la búsqueda de utilidad? Cuesta enlazar ambas tesis sostenidas por Bentham, aunque en su libro de 1780 se encarga fundamentalmente del desarrollo de una propuesta ética. 
recientemente llamada por Margaret Archer (2009)-, el interés de la comunidad se comprende únicamente como la suma de los intereses de los diversos miembros que la componen (Bentham, 2000, p. 14-15) ${ }^{7}$.

El principio de utilidad sitúa el foco ético y político del utilitarismo en el bienestar social. Ahora bien, el enfoque propuesto por Bentham se sostiene sobre dos pilares más: un objeto específico de evaluación ética y una forma de calcular el bienestar individual y colectivo.

En cuanto al objeto de evaluación ética, el filósofo inglés sostiene que la tendencia general de un acto es más o menos perniciosa, de acuerdo con la suma total de sus consecuencias: es decir, de acuerdo a la diferencia entre la suma de aquellas que son buenas y la suma de aquellas que son malas. (Bentham, 2000, p. 61) ${ }^{8}$

Por lo tanto, en agudo contraste con la moral deontológica -esto es, aquella que califica como buenos o malos ciertos comportamientos en general, sin considerar sus consecuencias particulares (Spaemann 2005)-, Bentham propone evaluar la moralidad de un acto observando el balance entre los efectos positivos y negativos que produce. Una gran dificultad de este proyecto, notada ciertamente por su autor, es que las consecuencias de cada acto son infinitas y de múltiples tipos. Por ello, el filósofo inglés propone considerar únicamente las consecuencias relevantes, definidas por él como aquellos hechos materiales de placer o dolor, o los que tienen una influencia en la producción de placer y dolor (Bentham, 2000, p. 61).

El tercer pilar de la propuesta ética de Bentham es su metodología para calcular la utilidad individual y colectiva. El valor de cada placer y dolor, sostiene el filósofo, puede ser evaluado en sí mismo de acuerdo a cuatro criterios: intensidad, duración, certeza y proximidad. Pero, además de cada placer o dolor específico, es importante considerar la tendencia de efectos producida por ellos. En ese sentido, Bentham (2000, p. 32) opta por incorporar dos criterios a la evaluación: la fecundidad del placer o dolor observado -es decir, su probabilidad de ser

7 A pesar de que esta visión de la agrupación social tiene un fundamento individualista -ya que lo colectivo no es más que una suma de individuos-, cabe destacar que el énfasis en el carácter social del bien moral es lo que distingue más claramente al utilitarismo inglés -como hedonismo socialdel hedonismo individualista delineado por Epicuro (Cortina, 2000). 
seguidos por sensaciones del mismo tipo- y la pureza de los mismos -su probabilidad de llevar a sensaciones del tipo opuesto-. Finalmente, a estos seis criterios que permiten evaluar el nivel de placer obtenido en cada acto individual y su tendencia al mismo, se añade un último elemento ideado para estimar la utilidad colectiva: la extensión social del placer o dolor, esto es, el número de personas que son afectadas por él.

Una vez distinguidos estos siete criterios, Bentham (2000, pp. 32-33) propone un método para calcular la utilidad social que involucra cualquier acto. Esta medición se inicia observando en cada persona a) el valor de cada placer y cada dolor distinguible que parece ser producido directamente por el acto referido y b) el valor de cada placer y cada dolor que parece seguirse con posterioridad al acto -es decir, su fecundidad y pureza- ${ }^{9}$. Posteriormente, se procede a c) sumar todos los placeres, por un lado, y todos los dolores, por el otro, para ver hacia qué polo - positivo o negativo- se inclina la utilidad en cada individuo. Luego de haber realizado este proceso a nivel personal, propone Bentham d) sumar el total de placeres de todas las personas interesadas en el acto y contrastarlo con el total de dolores de los mismos. El resultado de este cálculo y balance representará la utilidad colectiva.

Este énfasis en la medición y el cálculo social de la utilidad explica que Bentham haya sostenido, en el prefacio de un texto anónimo en 1776 (A Fragment on Goverment), lo que describe como un axioma fundamental para medir la rectitud de una acción: que persiga la mayor felicidad para el mayor número ${ }^{10}$. Si bien desde un artículo de Robert Shakleton, en 1972, se discute si el autor intelectual de esta frase sería Cesare Beccaria -en su libro "Dei delitti e delle pene" $(1768)^{11}-$, es cierto que dicha formulación sintetiza bastante bien el núcleo de la

9 A pesar de lo que se cree comúnmente, Bentham era consciente de las limitaciones de estos datos: la subjetividad de la experiencia de placer, su incapacidad de manifestarse directamente a un observador externo y su expresión socialmente mediada por creencias y actitudes, al menos (Quinn, 2014).

10 La frase completa es: "the greatest happiness of the greatest number, that is the measure of right and wrong” (Bentham, 1891, p. 93).

11 La frase de Beccaria (1993) tomada como referencia es la siguiente: "la felicidad mayor colocada en el mayor número debiera ser el punto a cuyo centro se dirigiesen las acciones de la muchedumbre" (p. 55). 
doctrina ético-política de Bentham: lo correcto es perseguir la mayor utilidad individual de una manera colectivamente agregada.

\section{Críticas al utilitarismo y el problema de los derechos humanos}

Como hemos visto, El nú Cleo del argumento de Bentham se estructura sobre tres pilares: un foco ético y político -el bienestar social, entendido como utilidad o felicidad agregada-, un objeto de evaluación -las consecuencias de las acciones- y una forma de cálculo - la suma de placeres y dolores, tanto a nivel individual como colectivo-. Todos estos elementos confluyen en la premisa utilitarista clásica, según la cual las elecciones se juzgan en función de la suma de utilidades generadas.

Cada uno de estos principios ha sido cuestionado por diversos teóricos sociales contemporáneos. Amartya Sen (2000), por ejemplo, critica la reducción del bienestar a la felicidad: según él, "la medida mental del placer o del deseo es demasiado maleable para ser una guía sólida de las privaciones y desventajas", ya que "nuestros deseos y capacidades para experimentar el placer se adaptan a las circunstancias, sobre todo para hacer que la vida resulte soportable en las situaciones adversas" (p. 86). Los estudios científicos sobre el bienestar subjetivo suelen confirmar esta idea, mostrando que los niveles de felicidad personal pueden variar sin que existan cambios relevantes en la calidad de vida: ello se ha explicado por la adaptación psicológica a las circunstancias, como señala Sen, pero también porque los niveles de bienestar subjetivo son afectados por cambios en el entorno social -debido a las comparaciones interpersonales- y porque existe una diferencia empírica entre la evaluación del placer y el dolor en tiempo presente y aquellas que se realizan a posteriori -basándose en el recuerdo de vivencias pasadas- (Beytía, 2015).

Otros teóricos, como James Lenman (2000), Robert Spaemann (2005) y Giovanni Sartori (2002) han criticado el enfoque en las consecuencias. Para los dos primeros, cuando consideramos el conjunto de efectos de nuestro obrar "andamos a tientas", ya que ellos son sumamente imprevisibles como para calcularse en la vida cotidiana y son tan complejos, que es posible sufrir a largo plazo consecuencias de signo contrario a las que se observan inmediatamente. Esto último, según Spaemann, podría utilizarse incluso para justificar el desarrollo de crímenes que 
persigan fines beneficiosos en el largo plazo. En sintonía con este diagnóstico, Sartori (2002) remarca la irrelevancia práctica del foco en las consecuencias: según él, desde las premisas utilitaristas se podrían extraer todo tipo de consecuencias deseadas, pudiendo justificar incluso decisiones políticas contrarias ${ }^{12}$.

En tercer lugar, un grupo de filósofos ha cuestionado la viabilidad y deseabilidad del cálculo utilitarista. Por un lado, ha existido escepticismo metodológico: Aladastair McIntyre (1987), por ejemplo, duda que los diversos placeres y felicidades se puedan medir y comparar entre sí -al no existir una escala adecuada que permita la agregación-, mientras que Michael Sandel (2011), con argumentos similares, duda que sea posible sumar felicidades entre diversos individuos. Por otro lado, se ha planteado un cuestionamiento a la deseabilidad de basar los juicios morales en la agregación de utilidades: un buen representante al respecto es John Rawls (1995), quien argumenta que la preocupación utilitarista por el total general de felicidad produce indiferencia ética frente a qué sector de la población obtiene los beneficios y en qué momento. ¿Es acaso equivalente, en términos de justicia social, que la utilidad de una acción sea recibida por quienes tienen mayor bienestar, a que la reciban los más carentes de la sociedad ${ }^{13}$ ?

Si bien es relevante considerar este trasfondo crítico del utilitarismo, no será posible evaluar aquí la pertinencia de cada argumento señalado. Es indispensable, no obstante, desarrollar en detalle otro de los reproches más populares que se han hecho a la doctrina defendida por Bentham: su incompatibilidad lógica con la defensa irrestricta de los derechos humanos.

Sobre este tema, la lista de autores que se ha pronunciado es larga -incluyendo a John Stuart Mill (1991 [1863]), John Rawls (1995 [1971]), Herbert Hart (1979), Raymond Frey (1984b), Amartya Sen (2000 [1999]) y Michael Sandel (2011), entre otros-. Lo primero que habría que considerar -si es que se quiere comprender a fondo esta crítica-, es que la moral utilitarista presupone que

12 Una defensa actual del consecuencialismo, especialmente contraria a los argumentos de James Lenman (2000) y estadísticamente fundamentada, puede verse en Bruch-Brown (2014).

13 La indiferencia utilitarista frente a qué sector de la población obtiene los beneficios también ha sido rescatada como algo positivo en la filosofía contemporánea. Por ejemplo, Peter Singer considera esta "imparcialdad" como una "igualitaria consideración de intereses" (Hooker 2014). 
el placer y la exención de sufrimiento son las únicas cosas deseables como fines; y que todas las cosas deseables [...], son deseables ya bien por el placer inherente a ellas mismas, o como medios para la promoción del placer y la evitación del dolor. (Mill, 1991, p. 46)

Debido a este principio, el enfoque utilitarista no concede importancia intrínseca a los derechos y libertades, que solo son valorados indirectamente y en proporción a su influencia en las utilidades (Sen, 2000, cap. 3). Bentham (2002) defiende explícitamente esta posición en su texto "Nonsense upon Stilts" ${ }^{14}$, donde -haciéndose parte de una ola de intelectuales europeos críticos a los derechos humanos, como Savigny o Marx (Cruz, 2006) - argumenta que los preceptos naturales carecen de todo fundamento ontológico, salvo en la medida en que reflejan deseos personales de quienes los propagan. La idea de que existan derechos naturales e imprescriptibles sería para él un disparate retórico; sin el apoyo de leyes reales (proclamadas y defendidas por el Estado), de un derecho sustantivo, no serían más que quejidos impresos. Al plantear esto, sin duda Bentham tenía en mente la Revolución francesa, suceso histórico en donde el lenguaje del iusnaturalismo se había utilizado para teñir de respetabilidad las pasiones violentas y egoístas (Schofield, 2003).

Hay que tratar este punto con mayor detalle. La teoría de la vida utilitarista -tal como la llama Mill- no es incompatible con la defensa de los derechos humanos -y ello puede comprobarse, como se verá posteriormente, al leer los escritos de Bentham sobre el panóptico-. No obstante, desde la visión utilitarista dichos derechos no pueden comprenderse como normas inapelables o como expresión de cualidades humanas inalienables, sino como "preceptos que la experiencia muestra que debieran ser respetados estrictamente, abandonándose solo en circunstancias excepcionales si con ello se maximiza la suma de ventajas" (Rawls, 1995, p. 37). En otras palabras, se trataría de normas empiricamente defendibles, aunque extraíbles en casos límite, específicamente cuando entran en contradicción con el aumento del beneficio colectivo. John Stuart Mill (1991), por ejemplo, en su explicación del utilitarismo es muy claro al defender esta idea: "tener derecho [...] es tener algo cuya posesión ha de serme defendida por la sociedad. [...] Si quien presenta objeciones continúa preguntando por qué debe ser

14 Previamente publicado bajo el título “Anarchical Fallacies” (1843), escrito entre 1791 y 1792. 
así, no puedo ofrecer otra razón que la utilidad general" (p. 118). De tal modo, el utilitarismo establece una relación jerárquica entre la utilidad colectiva y los derechos: los segundos serían defendibles mientras no limiten la maximización de la primera.

El punto crítico de esta discusión se alcanza cuando determinadas acciones maximizan las ventajas sociales al costo de abandonar los derechos humanos. Michael Sandel (2011) ha ofrecido un ejemplo bastante instructivo al respecto: en la antigua Roma echaban a los cristianos a los leones en el Coliseo para divertir a la muchedumbre. Imagine el correspondiente cálculo utilitario: sí, los cristianos sienten un dolor espantoso cuando los leones los muerden y devoran; pero tenga en cuenta el éxtasis colectivo de los vociferantes espectadores que abarrotan el Coliseo. Si hay suficientes romanos que sacan suficiente placer del violento espectáculo, ¿hay alguna razón por la que un utilitarista pueda condenarlo? (p. 49)

Siguiendo fielmente el utilitarismo de Bentham -y aceptando que la suma de placeres en el Coliseo supera la de los dolores-, no habría motivos para dejar de torturar y matar cristianos en el circo romano, e incluso podría fomentarse justificadamente esa práctica. Esta situación, en donde se aprueba moralmente el acto de torturar y matar si ello provee mayores efectos positivos que negativos en términos de placer y dolor agregado, ha sido denominada en la literatura como sacrificio utilitarista (Frey, 1984b) y representa una conclusión lógica de esta doctrina en la medida en que para ella la utilidad separada de cada individuo solo tiene importancia como fragmento de lo que realmente es importante: el total agregado de placer o felicidad (Hart, 1979). Si bien es posible que en algunos escritos Jeremy Bentham haya parecido lejano a este procedimiento sacrificial, la coherencia entre este rechazo y su doctrina difícilmente podría sostenerse.

Una defensa teórica imaginable, dada la tradición empirista de los utilitaristas, podría basarse en un argumento de inducción histórica: en todas las sociedades que se conocen, el respeto de la vida humana aumenta la felicidad. Pero jeste ha sido un respeto universal, o solamente reservado para un grupo selecto de hombres libres (en donde, por ejemplo, no estaría incluido el conjunto de prisioneros cristianos)? ¿Y qué pasaría si efectivamente en la antigua Roma, como excepción histórica, el público del Coliseo hubiera sentido un intenso, perdurable y fecundo placer con los espectáculos de sangre humana, más fuerte que el dolor 
agregado de los pocos seres humanos sacrificados y también más potente que la felicidad social generada por la garantía estable de los derechos humanos? En ese caso, lo correcto para los romanos hubiera sido matar cristianos. De este modo, la respuesta utilitarista queda supeditada a una evaluación circunstancial, caso a caso, que no puede asegurar estándares morales mínimos por medio de la promoción de un principio ético general. Esto último equivaldría a cambiar su postura consecuencialista por una de orientación deontológica; es decir, a transgredir uno de los tres pilares característicos del utilitarismo clásico.

Otra posible defensa sería destacar -como hacen los llamados utilitaristas de normas $^{15}$ (Hooker, 2008; 2011; 2014) - las consecuencias positivas que tendría la conservación de derechos fundamentales en el largo plazo: la defensa de la vida humana, de una manera sostenida en el tiempo, termina generando más placer que su vulneración colectiva de forma ocasional; entonces se justificaría proclamar una norma de protección vital, a pesar de que el acto circunstancial del circo genere más placer que dolor en el corto plazo. Pero ¿y si en el Coliseo hubiera tanto público, tanto placer y tanta fecundidad del mismo, como para superar los beneficios que genera el respeto de la vida de manera sostenida? ¿O si el espectáculo se hiciera con mayor regularidad, hasta el punto de sobrepasar la utilidad colectiva asociada al derecho de conservar la vida? En esos casos, nuevamente lo correcto sería matar cristianos. De hecho, el argumento del utilitarismo de normas podría ser utilizado para respetar los derechos humanos siempre y cuando ello generara mayor utilidad social; sin embargo, también podría usarse para aumentar el número de sentencias en el circo romano, al menos hasta superar los niveles que alcanzaría la conservación del derecho universal a la vida.

Estos ejercicios hipotéticos se podrían repetir indefinidamente y darían el mismo resultado: desde el utilitarismo clásico formulado por Bentham brota indefectiblemente un límite ético para los derechos humanos, dado que ellos se jerarquizan por debajo -y por tanto, en último término quedan al servicio- del principio soberano de la utilidad colectiva.

15 Los utilitaristas de normas o de reglas, son los que conciben los actos como permisibles, necesarios o incorrectos dependiendo de si son permitidos, requeridos o prohibidos por las normas o reglas sociales que maximizan la utilidad colectiva (Hooker, 2014, p. 126). 
HASTA EL MOMENTo se ha sistematizado la crítica normativista al utilitarismo, fortalecida en las últimas décadas por el trabajo de diversos teóricos sociales y políticos. Esta confrontación fue descrita en la filosofía moral anglosajona -atendiendo especialmente a los argumentos filosóficos de Robert Nozick (1974) y Ronald Dworkin (1977) - como "el cruce entre la antigua fe en el utilitarismo y la nueva fe en los derechos" (Hart, 1979, p. 846). Como se ha mencionado, este cruce o contraste moral no se sustenta únicamente en los escritos críticos al utilitarismo: el mismo Bentham (2002) sostuvo que los derechos naturales e imprescriptibles eran un absurdo retórico, un disparate sobre zancos [nonsense upon stilts]. Pero este rechazo al iusnaturalismo podría perfectamente haber sido únicamente un planteamiento teórico, sin mantener congruencia con las propuestas políticas desarrolladas por el filósofo inglés. En ese contexto, cobra relevancia la pregunta de este artículo: ¿podría sostenerse la incompatibilidad entre utilitarismo y derechos humanos observando una propuesta política específica que haya desarrollado Bentham?

Como buen representante del espíritu reformista del siglo XVIII, Bentham elaboró un original proyecto arquitectónico destinado a transformar el sistema penitenciario europeo. Se trataba de una prisión que permitiría maximizar la seguridad y el uso eficiente de los recursos, promoviendo además una reforma moral entre los presos. Como bien puede notarse en el prefacio a su colección de cartas sobre el tema, las expectativas que tenía Bentham (1989) sobre este proyecto no eran pocas:

enmendar las costumbres, preservar la salud, fortalecer la industria, difundir la instrucción, disminuir la carga pública, asentar de algún modo la economía sobre una roca, no cortar sino desenredar el nudo gordiano de las leyes de asistencia pública; y todo esto igracias a una simple idea arquitectónica! (p. 75)

¿Pero qué implicaba esta propuesta tan beneficiosa? El grueso del proyecto fue sintetizado en el folleto publicado en 1791 por la Asamblea Nacional de Francia: se trata de un edificio circular, o más bien dos edificios encajados uno en otro. Los aposentos de los presos formarían el edificio de la circunferencia con una altura de seis pisos. Se les puede representar como celdas abiertas del 
lado interior, porque un enrejado de hierro poco macizo las expone por entero a la vista. [...] Una torre ocupa el centro: es la vivienda de los inspectores [...]. A su vez, la torre de inspección está circundada por una galería cubierta con una celosía transparente, la cual permite que la mirada del inspector penetre en el interior de las celdas y que le impide ser visto, de manera que con una ojeada ve la tercera parte de sus presos y, al moverse en un reducido espacio, puede ver a todos en un minuto. (Bentham 1989, pp. 41-42)

La prisión así descrita fue bautizada por Bentham (1989) como panóptico debido a "su ventaja esencial: la facultad de ver, con solo una ojeada, todo lo que allí ocurre” (p. 42). Esta maximización del principio de inspección implicaba, como el propio Bentham (1989) señala, que los presos perdieran, en efecto, "la fuerza para obrar mal y casi la idea de desearlo" (p. 42). Esa sería la principal virtud del panóptico.

De forma añadida, el proyecto involucraba una serie de ventajas colaterales: vigilancia omnipresente -dado que la presencia de inspectores no es comprobable visualmente por los presos, la idea de que estén en la torre central puede ser tan eficaz como su presencia real-, eficacia organizativa entre los inspectores, facilidad de participación de los jueces y magistrados - ya que se elimina para sus visitas la repugnancia y el peligro-, maximización del tiempo, facilidades para la comunicación, seguridad del edificio - contra maquinaciones internas y ataques exteriores-, ahorro de servicio doméstico y de distribución del agua, entre otros muchos aspectos descritos detalladamente por Bentham (1989, pp. 42-47).

Sería bastante superficial evaluar las consecuencias de este proyecto penal sin considerar su vínculo con la perspectiva filosófica de su autor, ni sopesar las críticas más relevantes que se han formulado contra dicha doctrina. Después de todo, el proyecto fue diseñado en 1786, solo seis años después de que Bentham publicara las líneas fundamentales de su sistema moral y político, y las críticas contemporáneas al utilitarismo son las que actualmente nos animan a observar la posible incompatibilidad entre la propuesta penitenciaria de Bentham y la defensa irrestricta de los derechos humanos.

Por otra parte, esta propuesta política también debe ser interpretada considerando su particularidad histórica. Como se constata en las cartas de Bentham, en 1791 el filósofo promovía la construcción de este proyecto penitenciario en Francia. Esto significa que en el mismo período en que Bentham escribía su principal 
manuscrito crítico de los derechos humanos - "Nonsense upon Stilts", elaborado entre 1791 y $1792-$, intentaba convencer a la Asamblea Nacional de la implementación del panóptico en Francia, nación que recientemente había proclamado la Declaración de Derechos del Hombre y del Ciudadano (1789) - preceptos considerados en dicho documento como naturales, inalienables y sagrados-.

\section{Un humanitarismo que instrumentaliza los derechos humanos}

Una leCtURA DeTAllada de El panóptico permite rescatar dos posturas de su autor frente a los derechos humanos: 1) Bentham, muy lejos de ser un hombre despótico o un comerciante sin alma, parece ser un humanitario convencido y, más aún, un promotor persistente de los derechos humanos ${ }^{16}$; 2) no obstante, su defensa de estos preceptos es primordialmente instrumental; es decir, no considera que ellos tengan un valor inherente, sino que funcionan como medios para perseguir la felicidad colectiva -que es simplificada recurrentemente como maximización económica-. Ambas posturas se desarrollan entrelazadas en casi todos los pasajes donde Bentham problematiza el tema, aplicándose a materias diversas y fundamentales, como la mantención de la vida, la salud, el trabajo y la educación.

Evaluemos primero el humanitarismo del proyecto. Es notable cómo, en la descripción del panóptico, Bentham (1989) continuamente resalta la brutal condición en que vivían los presos de su época, calificándola como nociva, peligrosa, injusta y poco humanitaria. En su opinión, los reclusos "han sido hasta ahora los más infelices de todos los seres" (p. 54). Quizás donde más puramente se demuestran las intenciones humanitarias del filósofo, es cuando discute la alimentación de los presos:

Casi siempre se ha creído que debe limitarse la cantidad y dar porciones fijas; eso es un auténtico acto inhumano para quienes esa ración no satisface; es un castigo muy injusto que nada tiene que ver con el grado de delito, sino con la fuerza o la debilidad de un hombre [...]. Es una verdadera tortura, con la única diferencia de que, en ese caso, la tortura va infligida al interior del estómago en vez de a los brazos y a las piernas. (Bentham, 1989)

16 Esto podría haber sido una estrategia retórica: después de todo, Bentham buscaba convencer del proyecto a una asamblea que había aprobado recientemente los Derechos del Hombre y del Ciudadano (1789). 
Esta visión humanitaria es sistematizada en su propuesta de una norma de benevolencia, la cual especifica que, si bien los prisioneros no deben

gozar de condiciones mejores que las de los individuos de su misma clase y que viven en un estado de inocencia y de libertad, [...] la condición ordinaria de un preso condenado a trabajos forzados por largo tiempo no debe ir acompañada de sufrimientos corporales nocivos o peligrosos para su salud o vida. (Bentham, 1989, p. 49)

Ahora bien, esta norma de benevolencia no es justificada por la dignidad humana o la inviolabilidad de la persona, sino que se concibe, desde su inicio, como protección de la vida y la salud para no interferir en el correcto funcionamiento del sistema penal. En palabras de Bentham (1989):

la norma de benevolencia está fundada en las más sólidas razones. Los rigores que afectan la vida y la salud de los presos, encerrados en la incomunicación de una cárcel, son contraproducentes para el principal objetivo de las penas legales, que es el ejemplo. (p. 49)

La vida y la salud, no obstante, son solo los primeros bienes humanitarios que Bentham defiende instrumentalmente, es decir, aludiendo a su utilidad para conseguir otros fines. También ello sucede con el trabajo digno y la educación. Su negación al trabajo forzado, por ejemplo, es justificada por la eficiencia laboral que podrían conseguir los contratistas: "el trabajo forzado no está hecho para las prisiones: si usted tiene necesidad de hacer grandes esfuerzos, lo conseguirá con recompensas y no con penas" (Bentham, 1989, p. 61). Y en cuanto a la educación de los presos, ella tampoco es justificada como un bien en sí misma, si no que como un proceso que podría aumentar la utilidad colectiva. Ello queda claro en el provocativo cuestionamiento de Bentham (1989): “'por qué negaríamos el beneficio de la instrucción a hombres ignorantes que podrían transformarse en miembros útiles de la sociedad, gracias a una nueva educación?” (p. 66).

En contraposición a estos objetivos humanitarios -vida, salud, trabajo y educación-, que son justificados según su aporte al placer colectivo, Bentham parece concebir el bienestar económico como algo deseable por sí mismo ${ }^{17} \mathrm{y}$ cuya persecución genera los criterios apropiados para administrar otros bienes

17 Eso sugieren algunas frases del texto, como esta: "la norma de economía, siempre importante en sí" (Bentham, 1989, p. 50). 
fundamentales. En esa línea, el filósofo propone que no se establezcan límites a los administradores privados de las cárceles en cuanto al tipo de labor que le exigen a los prisioneros:

no hay razón [sostiene Bentham] para prescribir al empresario el tipo de trabajos en los cuales debe ocupar a sus presos, porque su interés le indicará cuáles son los más lucrativos. Si el legislador empieza a reglamentar, siempre se equivocará. (Bentham, 1989, p. 60)

Ese pasaje permite aclarar que, desde la perspectiva del utilitarismo benthamiano, la "equivocación" más relevante consiste en no conseguir el mayor beneficio económico de los trabajos penales, siendo preferible que los legisladores directamente se nieguen a establecer límites al criterio de maximización económica.

El núcleo de esta propuesta no es la formación de una jerarquía de valores -que implicaría una diversidad de principios ordenados según su grado de importancia-, sino derechamente un monopolio moral de los criterios económicos: ellos resuelven la rectitud de los objetivos políticos (incluidos los bienes fundamentales) y no necesitan de un criterio externo para evaluar o justificar su propia rectitud. De este modo, la justicia social quedaría ajustada a la economía, generando un punto ciego sobre sí misma: no se pueden evaluar los avances económicos como morales o inmorales, ya que ellos mismos representan el criterio de la moralidad. Bajo este modelo, no existirían aumentos económicos perversos, ni decisiones justas que impliquen una reducción social monetaria. La economía únicamente $e s$, mientras que los derechos fundamentales quedan abiertos al cuestionamiento por el deber ser.

Sin embargo, sería incorrecto asumir que el privilegio de la lógica económica en la administración de bienes fundamentales implica necesariamente consecuencias antihumanitarias. Bentham cree, de hecho, justamente lo contrario. La misma vida de los presos, argumenta, podría ser mejor mantenida con un sistema que proporcione incentivos económicos para su cuidado.

Los seguros sobre la vida de los hombres [sostiene enfáticamente] son un bello invento que se puede aplicar a numerosos usos, pero sobre todo en caso de que se trate de unir el interés de un hombre con la conservación de muchos. (Bentham, 1989, p. 54)

Como ejemplo, propone que cada año se dé al empresario que administra el panóptico una suma de dinero por cada persona que murió el año anterior en su 
cárcel, pero exigiendo que a fin de año él devuelva la misma cantidad por cada individuo muerto en el nuevo período. De tal forma, existiría un incentivo económico para preservar la vida de los presos. Y consciente de que existirían personas que reprobarían esta propuesta por establecer una "economía de la vida humana”, Bentham (1989, p. 54) contraargumenta: “iqué dinero podría usted deplorar menos que aquel por el cual podría adquirir la conservación y el bienestar de varios hombres?".

La defensa benthamiana de la maximización de utilidades económicas como criterio que justifica los derechos humanos es finalmente confirmada en su apreciación de los castigos. Nuevamente aquí, Bentham muestra una posición humanitaria que no se justifica por la dignidad humana de los presos, sino en virtud de la utilidad colectiva -considerada simplificadamente como utilidad económica-. Evaluando moralmente el procedimiento de castigar a los prisioneros con una soledad sostenida en el tiempo, el filósofo inglés comenta:

la soledad absoluta, tan contraria a la justicia y a los derechos humanos cuando hacemos de ella un estado permanente, queda incluso dichosamente refutada por las más grandes razones económicas; exige un gasto considerable en edificios; dobla los gastos de alumbrado, limpieza y ventilación; restringe la selección de trabajos por el espacio limitado de las celdas y excluye profesiones que exigen la reunión de dos o tres obreros. (Bentham, 1989, p. 57)

Protección de la vida y la salud, educación y trabajo digno, además de una alimentación ajustada a las necesidades personales, un sistema de seguros de vida y una moderación de ciertos castigos. Todas estas propuestas se orientan en la misma dirección que la protección de los derechos fundamentales y podrían tener, en efecto, consecuencias similares. Sin embargo, su justificación no se basa en la dignidad de la persona o en la inviolabilidad de seres humanos, sino en la promoción de la felicidad colectiva, que en el caso del panóptico es simplificada como maximización de beneficios económicos. 
LA PREGUNTA INICIAL de este ensayo fue si la propuesta arquitectónica ideada por Bentham era o no compatible con la defensa irrestricta de los derechos humanos. La respuesta debe darse con ciertos matices. En la formulación del panóptico, Bentham se muestra como promotor de los derechos humanos - protegiendo la vida y fomentando la salud, el trabajo adecuado y la instrucción de los presos-. Esta posición humanitaria podría parecer incoherente con su doctrina moral, conocida por ser una de las más radicales críticas a los derechos naturales (Cruz, 2006). Sin embargo, no es así. La incompatibilidad entre utilitarismo y iusnaturalismo esbozada por Bentham no se basa en el contenido de las normas, sino en su interpretación como preceptos naturales e imprescriptibles. Y cada vez que Bentham promueve dichos derechos en su propuesta penitenciaria, lo justifica aludiendo a sus efectos positivos en la utilidad colectiva-que en el caso de la reforma penal es interpretada mayoritariamente como eficiencia económica-. De allí que Bentham no tenga problemas en promover el trato humanitario, aunque no lo haga irrestrictamente ni porque crea en una base natural de dignidad humana, sino porque ello funcionaría, para sus específicas condiciones históricas, como un medio para la maximización social del bienestar.

Esta propuesta implica un limite ético para los derechos humanos, ya que ellos no podrían justificarse si entran en contradicción con la persecución de la utilidad social, lo cual elimina la opción ética de sacrificar el placer colectivo por la garantía de la dignidad humana -situación que podríamos denominar sacrificio iusnaturalista, por oposición al ya mencionado sacrificio utilitarista ${ }^{18}$-. Específicamente, la jerarquía moral propuesta por Bentham en El panóptico deriva, al igual que en sus escritos morales, en un cuestionamiento de la universalidad e irrevocabilidad de los derechos humanos. Dado que los intereses individuales son diferentes para cada persona y van cambiando a partir de la sucesión de procesos históricos, también van transformándose, por un lado, las propiedades que tienen los objetos para producir placer o dolor en cada persona - es decir su utilidad individual-, y por el otro, el interés y la utilidad colectivos -que no son

18 Que refiere a la aprobación moral del sacrificio de vidas humanas si ello aumenta la utilidad colectiva (Frey 1984b). 
para Bentham más que la suma de intereses y utilidades individuales-. Este proceso de permanente cambio en las utilidades implica que los derechos humanos, si son justificados por su promoción de consecuencias útiles para un grupo social, no podrían ser defendidos como principios universales - adecuados para todas las sociedades-, ni irrevocables - correctos para todas las épocas históricas-.

El panóptico de Bentham, de esta forma, emerge como algo más que "una simple idea arquitectónica": es la materialización coherente de un modelo moral sobre la sociedad que, en último extremo, está abocado a limitar el alcance de los derechos humanos, apuntando a su instrumentalización y relativización histórica o cultural. Desde él estos preceptos podrían ser defendidos circunstancialmente, pero no deberían ser considerados como fines en sí mismos ni como elementos estables del sistema jurídico, debido a que quedan condicionados al grado de eficiencia económica que sean capaces de generar en una colectividad particular y un período en específico, es decir, a un elemento que varía según la situación social e histórica de referencia.

\section{Referencias}

Archer, M. (2009). Teoría social realista. El enfoque morfogenético. Santiago de Chile: Ediciones Universidad Alberto Hurtado.

Beccaria, C. (1993). Tratado de los delitos y de las penas. Buenos Aires: Heliasta. Bentham, J. (1843). Anarchical Fallacies. En: The Works of Jeremy Bentham vol. 2 (pp. 496-524). Edinburgh: William Tait.

Bentham, J. (1989). El panóptico. Puebla: Premia.

Bentham, J. \& Montague, F. C. (1891). A Fragment on Government. London: Oxford University Press.

Bentham, J. (2000). An Introduction to the Principles of Morals and Legislation. Kitchener: Batoche Books.

Bentham, J. (2002). Nonsense upon Stilts. En: P. Schofield, C. Pease-Watkin \& C. Blamires. (Eds.). Rights, Representation, and Reform. Nonsense upon Stilts and Other Writings on the French Revolution (pp. 317-398). Oxford: Clarendon Press. 
Beytía, P. (2015). El potencial político de la felicidad: fundamentos científicos y de aplicación gubernamental. Persona y Sociedad, XXIX(3), pp. 59-86.

Burch-Brown, J. (2014). Clues for Consequentialists. Utilitas, 26, pp. 1-15.

Cortina, A. (2000). Ética minima. Introducción a la filosofía práctica. Madrid: Tecnos.

Cruz, J. A. (2006). La crisis de la fundamentación de los derechos humanos en el siglo XIX. En: M. Moreno-Bonet \& M. R. González. (Eds.). La génesis de los derechos humanos en México (pp. 219-228). México: Universidad Nacional Autónoma de México.

Dworkin, R. (1977). Taking Rights Seriously. Cambridge, MA: Harvard University Press.

Dworkin, R. (1980). Is Wealth a Value? The Journal of Legal Studies, 9(2), pp. 191-226.

Epicuro. (1999). Carta a Meneceo. (Trad. P. Oyarzún). Onomazein, 4, pp. 403-425.

Frey, R. G. (Ed.). (1984a). Utility and rights. Minneapolis: University of Minnesota Press

Frey, R. G. (1984b). Introduction: Utilitarianism and Persons. En: Frey, R. G. (Ed.). Utility and rights (pp. 9-19). Minneapolis: University of Minnesota Press.

Godwin, W. (1793). An Enquiry Concerning Political Justice, and its Influence on General Virtue and Happiness. London: G. G. J. and J. Robinson. Online Library of Liberty. Recuperado de http://oll.libertyfund.org/titles/90

Hart, H. L. A. (1979). Between Utility and Rights. Columbia Law Review, 79(5), pp. 828-846.

Hooker, B. (2008). Rule-Consequentialism versus Act-Consequentialism. Politeia, 24, pp. 75-85.

Hooker, B. (2011). Rule Consequentialism. En: E. Zalta. (Ed.). The Stanford Encyclopedia of Philosophy. Recuperado de http://plato.stanford.edu/archives/win2016/entries/consequentialism-rule/

Hooker, B. (2014). Acts or Rules? The Fine-Tunning of Utilitarianism. En: J. Perry. (Ed.). God, the Good, and Utilitarianism: Perspectives on Peter Singer (pp. 125-138). Cambridge: Cambridge University Press.

Hume, D. (2006). Investigación sobre los principios de la moral. Madrid: Alianza. 
Hutcheson, F. (2004). An Inquiry into the Original of our Ideas of Beauty and Virtue. Indianapolis: Liberty Fund.

Kant, I. (2007). Fundamentación de la metafísica de las costumbres. Madrid: Pedro M. Rosario Barbosa.

Layard, R. (2005). La felicidad: lecciones de una nueva ciencia. México: Taurus.

Lenman, J. (2000). Consequentialism and Cluelessness. Philosophy and Public Affairs, 29, pp. 342-370.

Mäkinnen, J. \& Kakkurri-Knuuttila, M. L. (2013). The Defense of Utilitarianism in Early Rawls: A Study of Methodological Development. Utilitas, 25(1), pp. 1-31.

McIntyre, A. (1987). Tras la virtud. Barcelona: Crítica.

Mill, J. S. (1991). El utilitarismo. Madrid: Alianza.

MINVU [Ministerio de Vivienda y Urbanismo del Gobierno de Chile]. (2014).

Vivienda social en copropiedad. Memoria de tipologias en condominios sociales. Santiago de Chile: Ministerio de Vivienda y Urbanismo del Gobierno de Chile.

Nozick, R. (1974). Anarchy, State, and Utopia. New York: Basic Books.

Paley, W. (2002). The Principles of Moral and Political Philosophy. Indianapolis: Liberty Fund.

Posner, R. (1979). Utiliaranism Economics, and legal theory. Journal of Legal Studies, VIII (1), pp. 103-140.

Priestley, J. (1771). An Essay on the First Principles of Government: and on the Nature of Political, Civil, and Religious Liberty. London: J. Johnson. Online Library of Liberty. Recuperado de http://oll.libertyfund.org/titles/1767 Quinn, M. (2014). Bentham on Mensuration: Calculation and Moral Reasoning. Utilitas, 26, pp. 61-104.

Rawls, J. (1995). Teoria de la justicia. México: Fondo de Cultura Económica.

Sartori, G. (2002). La politica. Lógica y método de las ciencias sociales. Madrid: Fondo de Cultura Económica.

Sandel, M. (2011). Justicia: ¿hacemos lo que debemos? Madrid: Debate.

Schofield, P. (2003). Jeremy Bentham's “Nonsense upon Stilts". Utilitas, 15, pp. 1-26.

Sen, A. (2000). Desarrollo y libertad. Barcelona: Planeta. 
Sen, A. (2006). Reason, Freedom and Well-Being. Utilitas, 18(1), pp. 80-96.

Sen, A. (2014). La idea de la justicia. Buenos Aires: Taurus.

Shackleton, R. (1972). The Greatest Happiness of the Greatest Number: The History of Bentham's Phrase. Studies on Voltaire and the Eighteenth Century, 90, pp. 1461-1482.

Spaemann, R. (2005). Ética. Cuestiones fundamentales. Navarra: Eunsa. 